\title{
LEVANTAMENTO DAS MANIFESTAÇÕES PATOLÓGICAS PRESENTES EM UM CONDOMÍNIO RESIDENCIAL DE CASCAVEL - PR EXECUTADO EM PAREDES DE CONCRETO
}

\author{
DEZAN, IGOR \\ Aluno de Graduação \\ Centro Universitário Fundação Assis Gurgacz \\ Paraná; Brasil \\ ildezan@gmail.com \\ RACHID, LIGIA \\ Professora, Dra. \\ Centro Universitário Fundação Assis Gurgacz \\ Paraná; Brasil \\ ligia@fag.edu.br
}

\author{
PAGANIN, RICARDO \\ Professor, Me. \\ Centro Universitário Fundação Assis Gurgacz \\ Paraná; Brasil \\ ricardop@fag.edu.br \\ FORIGO, CAMILA \\ Professora, Me. \\ Centro Universitário Fundação Assis Gurgacz \\ Paraná; Brasil \\ camilaforigo@fag.edu.br
}

\section{RESUMO}

A partir do conhecimento sobre as possíveis falhas e suas respectivas causas, as chances de se cometerem erros, podem ser reduzidas. Este trabalho teve como objetivo a realização de uma inspeção visual in loco para levantamento das manifestações patológicas nas casas de um condomínio residencial de Cascavel-PR, executado em paredes de concreto. O estudo foi realizado com base na metodologia utilizada pelo IBAPE em sua Norma de Inspeção Predial, verificações bibliográficas e especificações técnicas, identificando os problemas, suas origens e recuperação da patologia mais crítica, apontando o método provável para corrigi-la. Com essa pesquisa, observou-se que as manifestações patológicas de maior frequência foram as fissuras (70\%) e os bolores (23\%), entretanto, as fissuras representam 18\% das anomalias classificadas como críticas, enquanto os bolores correspondem a 53\%. Com maior incidência nas fachadas e banheiros, os bolores refletem a ação das intempéries, reiterando a importância do processo de impermeabilização durante a execução da obra, visto que, as anomalias provenientes da umidade geram danos às edificações e principalmente à saúde dos usuários.

Palavras-chave: patologias, criticidade, fissuras, bolores.

\begin{abstract}
After knowing about possible failures and their causes, the chances of making mistakes, can be reduced. This research aimed to perform a visual inspection in loco to identify the pathological manifestations in the houses of a residential condominium of Cascavel-PR, executed in concrete walls. The study was conducted based on the methodology used by the IBAPE in its Building Inspection Standard, bibliographic verifications and technical specifications, identifying problems, origins and the recovery of the most critical pathology, indicating the probable correction method. With this research, it was found that the most frequent pathological manifestation were fissures (70\%) and mold (23\%), however, the fissures represent $18 \%$ of anomalies classified as critical, while molds tend to be $53 \%$. With a higher incidence on facades and bathrooms, mold reflects the action of the weather, reiterating the importance of the waterproofing process during a work execution, since anomalies descendants of humidity generate damages to buildings and especially to the health of users.
\end{abstract}

Keywords: pathologies, criticality, fissures, molds.

\section{INTRODUÇÃO}

Após a criação do programa Minha Casa Minha Vida pelo governo brasileiro em 2009, o sistema construtivo com paredes de concreto ficou mais presente nas obras e tem sido usado em grande escala no país. Este modelo apresenta como vantagens: rapidez de execução, redução de mão de obra, custos globais mais baixos, desempenho considerável, minimiza a geração de resíduos, além de produzir um modelo construtivo em escala, devido à industrialização do sistema (SAMPAIO, 2016). 
Macedo et al. (2018), destacam que os elementos de concreto nesse tipo de sistema construtivo, como em qualquer outro, estão sujeitos ao aparecimento de manifestações patológicas, que podem comprometer o desempenho e durabilidade das estruturas. Ainda de acordo com os autores, estes podem se originar em qualquer etapa da construção dos imóveis, principalmente durante a execução.

Atualmente, a engenharia civil tem evoluído de uma forma mais rápida, com isto é importante que se avalie o comportamento dos sistemas construtivos, uso de novos materiais, entre outros. Por isso, a maneira que se estuda patologia e a forma de comunicação dos estudos devem se adaptar a tais desenvolvimentos e às constantes atualizações dos materiais e sistemas construtivos disponíveis no mercado (BAKENS, 2015).

A partir do conhecimento sobre as possíveis falhas e suas respectivas causas, as chances de se cometerem erros, podem ser reduzidas.

Tendo em vista aos dados expostos anteriormente, o objetivo deste trabalho foi levantar as fendas e bolores existentes nas casas de um condomínio residencial localizado em Cascavel-PR, o qual é constituído por 402 casas, com aproximadamente 1.000 moradores, para verificar a frequência dos problemas e se os mesmos podem trazer insegurança para as pessoas que habitam as residências. Construído em 2009, o condomínio residencial foi executado a partir do sistema construtivo de paredes de concreto moldadas in loco, com a utilização de formas metálicas.

\section{FUNDAMENTAÇÃO TEÓRICA}

Patologia das edificações é a ciência que estuda as origens, as formas de apresentação, aspectos, possíveis soluções e como evitar que qualquer componente de uma edificação deixe de atender aos requisitos mínimos para os quais foi projetado (CAPORRINO, 2016).

De acordo com Sampaio (2016), mesmo com o avanço tecnológico das técnicas construtivas e o emprego de materiais de construção com maior controle de qualidade, ainda se observa um grande número de edificações apresentando patologias das mais variadas espécies. Grande parte dessas patologias é oriunda do mau planejamento ou má execução do serviço.

O sistema construtivo de paredes de concreto moldadas in loco, atende às atuais premissas do mercado, oferecendo as vantagens de uma metodologia construtiva voltada à produção de empreendimentos que têm alta repetitividade, como condomínios e edifícios residenciais (ABCP, 2008).

Neste item foram abordadas as anomalias com as maiores frequências de manifestação encontradas nas amostras deste estudo, assim como a classificação das falhas construtivas quanto às suas origens e grau de risco.

\subsection{Manifestações patológicas}

\subsubsection{Fendas}

Os problemas patológicos em estruturas de concreto se manifestam de forma perceptiva, permitindo que as devidas providências sejam tomadas. Um dos sintomas mais comuns é o aparecimento de fissuras, trincas, rachaduras e fendas (VITÓRIO, 2003).

De acordo com Pina (2018), fissura é o estado em que um determinado elemento estrutural apresenta abertura bem finas, alongadas e superficiais, com até no máximo 0,5 milímetros de largura. $\mathrm{O}$ autor alega que o risco de as fissuras serem problemáticas é muito baixo, pois elas não afetam necessariamente a segurança dos componentes das estruturas. Pina (2018), define trincas como sendo aberturas de $0,5 \mathrm{~mm}$ à $1,5 \mathrm{~mm}$ que indicam que o objeto está partido, podendo diminuir a segurança dos componentes da estrutura de um edifício. A ocorrência de fissuras e trincas na estrutura de concreto armado provoca uma redistribuição de tensões, onde toda a estrutura, ou parte dela, passa absorver a carga, modificando o comportamento estrutural previsto pelo projeto (TACCO e SILVA, 2016).

De acordo com Gonçalves (2015), as rachaduras têm características que as diferenciam das demais, possuem abertura acentuada e profunda. A dimensão da patologia é superior a $1,5 \mathrm{~mm}$, sendo que em alguns casos pode abrir fendas de um lado ao outro da parede. 


\subsubsection{Bolor}

Verçoza (1991), comenta que a umidade é o fator essencial para o aparecimento de mofo, bolores, eflorescências, entre outras manifestações patológicas. $\mathrm{O}$ autor, ainda identificou as origens das umidades nas construções, que podem ser trazidas, durante a construção: por capilaridade, por chuva, resultantes de vazamentos em redes hidráulicas, ou condensação.

O emboloramento nada mais é do que uma alteração que pode ser constatada macroscopicamente na superfície de diferentes materiais, sendo consequência do desenvolvimento de microrganismos pertencentes ao grupo dos fungos (SOUZA e SILVA, 2018).

\subsection{Classificação das falhas quanto às suas origens}

De acordo com Souza e Ripper (1998), as causas das patologias podem ser as mais diversas, desde o envelhecimento natural da estrutura, os acidentes e até mesmo a irresponsabilidade de alguns profissionais que optam pela utilização de materiais fora das especificações, na maioria das vezes alegando razões econômicas. Na norma de inspeção predial nacional, o IBAPE (Instituto Brasileiro de Avaliações e Perícias em Engenharia) classifica as anomalias em quatro categorias de acordo com a origem da manifestação das mesmas. São elas: endógenas, exógenas, naturais e funcionais.

\subsubsection{Endógena}

As anomalias endógenas são originárias da própria edificação (projeto, materiais e execução).

A etapa de concepção do projeto se refere à fase em que a edificação é gerada. Esta é a base de todo o resto, pois qualquer falha, nessa fase, haverá prejuízo no andamento das outras fases. As anomalias endógenas podem ser originadas devido a falhas. Pode-se citar como exemplos: má definição das ações atuantes ou de sua combinação mais desfavorável, escolha inadequada modelo analítico e deficiência de cálculo da estrutura (PINA, 2013).

Franca, Marcondes e Rocha (2011), descrevem as manifestações patológicas relacionadas aos materiais componentes e ao processo construtivo, como sendo diretamente ligadas ao desconhecimento às normas pelos profissionais que lidam com o assunto e a falta de cuidados na elaboração e aplicação do concreto. De acordo com os autores, na maioria dos casos, o cumprimento às normas poderia evitar ou desacelerar consideravelmente os mecanismos de degradação de estruturas (doenças).

\subsubsection{Exógena}

As anomalias exógenas são as originárias de fatores externos à edificação, provocados por terceiros (IBAPE, 2012).

Piancastelli (2005), explica que muitos problemas que surgem nas edificações, na fase de utilização, são originados pelos usuários, por meio de diversos fatores como: sobrecargas não previstas no projeto, ou seja, uso para fins não calculados no projeto; alterações estruturais indevidas em função das reformas; utilização de produtos agressivos na limpeza ou ainda derramamentos acidentais de produtos agressivos, falta de programação de manutenção adequada, falta de inspeções periódicas para deteç̧ão de sintomas patológicos, etc. O mesmo autor indica que para minimizar estas falhas, as construtoras deveriam pensar melhor no profissionalismo quando da entrega da chave aos usuários.

\subsubsection{Natural}

IBAPE (2012) classifica as manifestações patológicas naturais como originárias de fenômenos da natureza.

É inevitável que para a sobrevivência humana o homem interfira na natureza com o seu espaço habitável. Entretanto, cabe à conscientização dos usuários de que as manifestações patológicas não deixam de serem fatores causados pela natureza, intempéries, clima, sistemas vivos ou outros, e que, portanto a interferência do homem deve ser da maneira correta, conhecendo suas capacidades, sabendo como cuidar da relação das construções com estes ambientes, mantendo a durabilidade das estruturas (MAIDEL et al., 2009). 


\subsubsection{Funcional}

Originária da degradação de sistemas construtivos pelo envelhecimento natural e, consequente, término da vida útil (IBAPE, 2012).

O entendimento de Oliveira (2013), para vida útil é o período em que a estrutura conserva todas as características mínimas de funcionalidade, resistência e aspectos externos exigíveis. $\mathrm{O}$ autor ainda afirma que, as estruturas devem ser projetadas, construídas e operadas de forma que, sob as condições ambientais esperadas, elas mantenham sua segurança, funcionalidade e a aparência aceitável durante um período de tempo, sem requerer elevados custos imprevistos para manutenção e reparo.

\subsection{Diagnóstico}

Para diagnosticar uma manifestação patológica, Franca, Marcondes e Rocha (2011), utilizam-se de ensaios destrutivos e não destrutivos com o intuito de realizar o prognóstico das doenças nas edificações. Ainda os autores, reforçam que tais ensaios, podem ser utilizados para "fornecer parâmetros que estão associados aos processos de deterioração ou risco de danos às estruturas". Desta maneira, indicam que deve-se consultar especialistas para empregar a melhor técnica e com isso obter análises mais eficientes e confiáveis.

O IBAPE (2012), recomenda que durante a execução do laudo de vistoria do imóvel afetado sejam coletadas informações, por meio de questionários e entrevistas, junto aos usuários, síndicos, gestores prediais, e demais responsáveis técnicas e legais pela edificação.

O Instituto classifica-as de acordo com o risco oferecido aos usuários, ao meio ambiente e ao patrimônio, conforme o Tabela 1 .

Tabela 1: Classificação quanto ao grau de risco.

\begin{tabular}{l|l}
\hline Nível & Descrição \\
\hline Crítico & $\begin{array}{l}\text { Risco de provocar danos contra a saúde e segurança das pessoas e do meio ambiente; perda excessiva de desempenho } \\
\text { e funcionalidade causando possíveis paralisações; aumento excessivo de custo de manutenção e recuperação; } \\
\text { comprometimento sensível de vida útil. }\end{array}$ \\
\hline Médio & $\begin{array}{l}\text { Risco de provocar a perda parcial de desempenho e funcionalidade da edificação sem prejuízo à operação direta de } \\
\text { sistemas, e deterioração precoce. }\end{array}$ \\
\hline Mínimo & $\begin{array}{l}\text { Risco de causar pequenos prejuízos à estética ou atividade programável e planejada, sem incidência ou sem a } \\
\text { probabilidade de ocorrência dos riscos críticos e regulares, além de baixo ou nenhum comprometimento do valor } \\
\text { imobiliário. }\end{array}$ \\
\hline
\end{tabular}

\section{METODOLOGIA}

\subsection{Tipo de estudo e local da pesquisa}

Tratou-se de um estudo de caso para registro da existência de fendas e bolores aparentes surgidas nas residências de um condomínio residencial.

A pesquisa foi realizada pelo método qualitativo e quantitativo, onde foram entrevistados os moradores e levantadas as manifestações patológicas encontradas nas casas do condomínio a partir de uma inspeção visual in loco. Após a coleta das informações e dados, tendo como base as referências bibliográficas, as anomalias foram classificadas quanto suas origens, além de indicada a conduta recomendada para reparo da anomalia que apresentou maior risco. Outro objetivo da pesquisa foi identificar a frequência que estas falhas são encontradas nas casas visitadas.

\subsection{Caracterização do empreendimento}

O condomínio residencial está localizado na cidade de Cascavel, Paraná e conta com aproximadamente mil moradores, sendo estes distribuídos em 402 casas.

As casas são divididas em 3 modelos. Todos os modelos possuem: 01 sala de estar/jantar, 01 cozinha, 01 lavanderia, 01 varanda e garagem para dois veículos. A diferença entre os modelos é no número de dormitórios e a existência ou não de banheiros sociais conforme mostrado na Tabela 2 . 
Tabela 2: Modelos de residências.

\begin{tabular}{l|l|l|l}
\hline Modelo & Dormitórios e banheiro & Área & Quantidade de casas \\
\hline A & 02 quartos e 01 banheiro social & $46,72 \mathrm{~m}^{2}$ & 80 \\
\hline B & 02 suítes e nenhum banheiro social & $58,64 \mathrm{~m}^{2}$ & 120 \\
\hline C & 02 quartos, 01 suíte e 01 banheiro social & $66,91 \mathrm{~m}^{2}$ & 202 \\
\hline
\end{tabular}

A pesquisa se restringiu às casas de modelo $C$ que são 202 unidades com área de $66,91 \mathrm{~m}^{2}$ desta foram selecionadas em torno de $30 \%$.

Foram levantadas as fendas e bolores internos. A Figura 1 apresenta a planta baixa humanizada deste modelo.

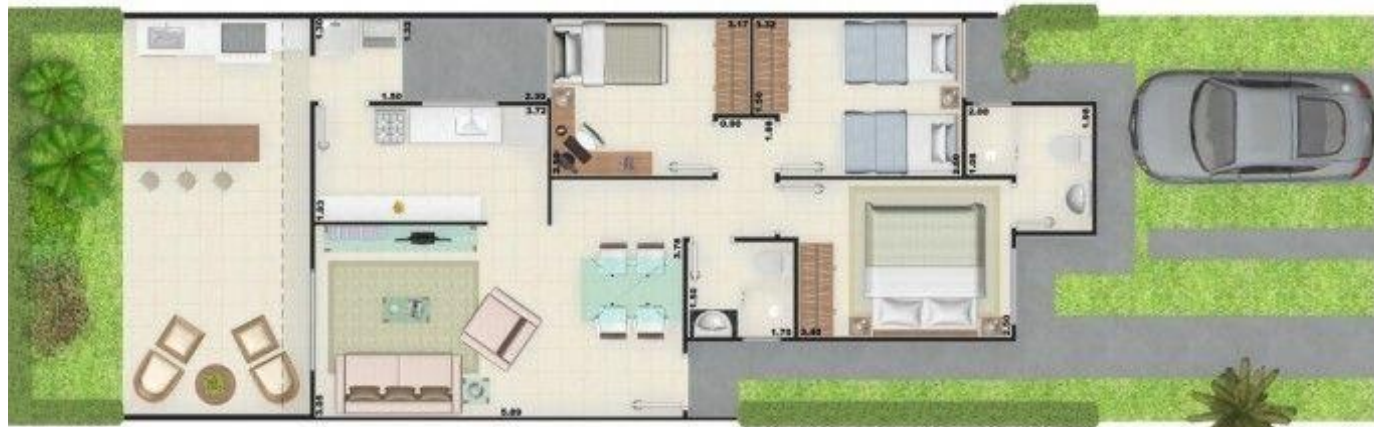

Figura 1: Planta baixa Modelo C.

\subsection{Instrumentos e procedimentos para coleta de dados}

A coleta de dados foi realizada com visitas técnicas in loco em cada uma das casas selecionadas e autorizadas pelos usuários. As visitas aconteceram nos meses de julho e agosto de 2019, com registro fotográfico dos problemas patológicos encontrados, bem como a quantificação e identificação das mesmas.

Para coleta de dados foi utilizada a Tabela 3, criada pelo autor. Trata-se da versão final do formulário, pois foi realizado um estudo piloto em três primeiras casas, sendo necessárias adequações no formulário inicial.

Tabela 3: Planilha para levantamento de dados.

\begin{tabular}{|c|c|c|c|c|c|}
\hline \multicolumn{6}{|c|}{ FORMULÁRIO PARA REGISTRO DAS MANIFESTAÇÕES PATOLÓGICAS } \\
\hline Amostra: & & Data: & & Horário: & \\
\hline \multicolumn{6}{|c|}{ ANAMNESE DO CASO } \\
\hline \multicolumn{6}{|c|}{ 1) A quanto tempo reside nesta casa? } \\
\hline \multicolumn{6}{|c|}{ 2) Recorda-se de algum fato ligado ao aparecimento do problema? } \\
\hline \multicolumn{6}{|c|}{ 3) Houve alguma reforma ou ampliação? } \\
\hline \multicolumn{6}{|c|}{ 4) Houve um recall voluntário por parte da construtora? } \\
\hline \multicolumn{6}{|c|}{ Observações: } \\
\hline \multicolumn{6}{|c|}{ LEVANTAMENTO } \\
\hline Número & Patologia & Ambiente & Interno & Externo & Observações \\
\hline & & & & & \\
\hline & & & & & \\
\hline & & & & & \\
\hline
\end{tabular}




\section{ANÁLISES E DISCUSSÕES}

\subsection{Frequência das manifestações patológicas}

Após a realização do levantamento de dados, conforme proposto no Item 3, as manifestações patológicas foram quantificadas, como se observa na Figura 2.

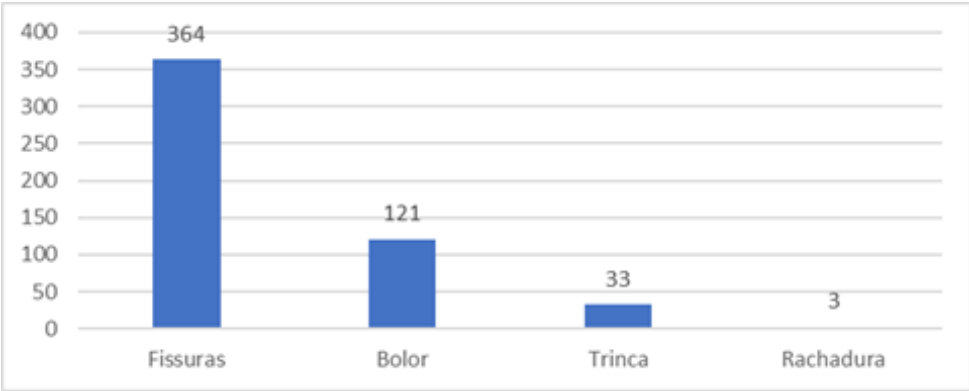

Figura 2: Frequência das manifestações patológicas.

Constatou-se que as fissuras, classificadas de acordo com as espessuras apresentadas no Item 2.1.1, apresentam maior incidência, correspondendo a 70\% das anomalias encontradas, estando presentes em 53 das 55 casas visitadas. As demais fendas apresentam ocorrências: para as trincas de $6 \%$, e as rachaduras $1 \%$. Já o bolor representou $23 \%$, sendo que das 121 unidades registradas, foram encontradas em 44 das 55 casas visitadas.

Analisando as fissuras separadamente, observa-se que a maior porcentagem corresponde às fissuras a 45 graus de esquadrias, representando 26\%, como mostrado no gráfico da Figura 3.

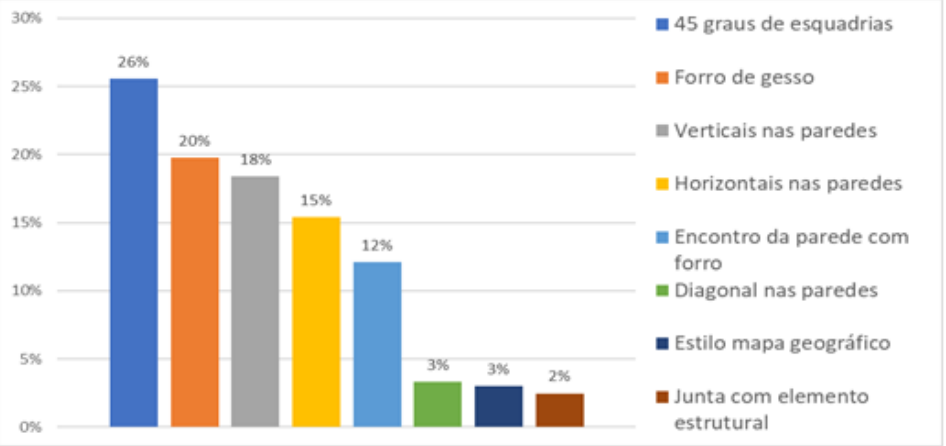

Figura 3: Tipos de fissura encontradas.

No caso de paredes de concreto as fissuras a 45 graus, conforme Figura 4, podem ser resultado da ausência da armadura de reforço, utilizada nas bordas das paredes, onde há vãos para portas e janelas, as quais são responsáveis por absorver os esforços na parede. Estes fazem o papel de verga e contraverga no combate das deformações estruturais (GOMES e MELO, 2016). De acordo com a NBR 16055 (2012) as armaduras devem ser instaladas nas faces superiores e inferiores das aberturas, com área de aço mínima de $0,5 \mathrm{~cm}^{2} \mathrm{em}$ cada face ancoradas nas paredes adjacentes.

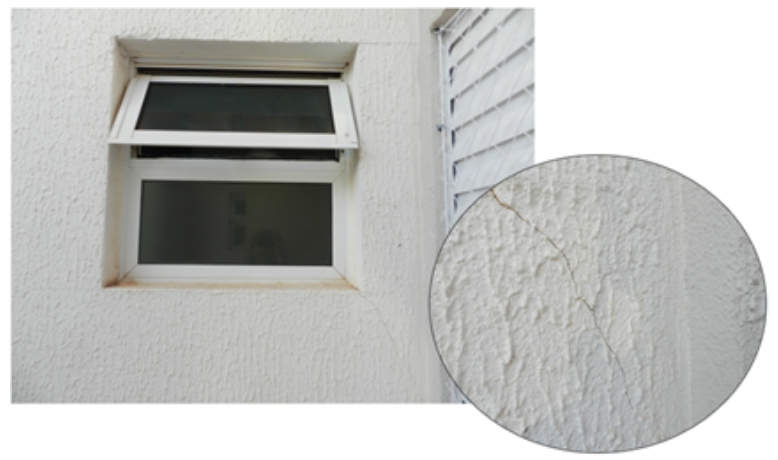

Figura 4: Fissura $45^{\circ}$ de esquadrias. 
Das 521 manifestações patológicas levantadas, 62\% encontram-se na região interior das casas visitadas, ilustradas na Figura 5. Entretanto, verificou-se que o maior número de patologias foi registrado nas fachadas, representando 137 das falhas encontradas (26\%). Estas fachadas estão expostas às intempéries, onde ocorre a variação de temperatura no painel de concreto, sendo que este é um material com baixa condutividade térmica. As variações térmicas em elementos de concreto geram tensões nas peças e consequentemente levam ao aparecimento de fissuras e outras patologias (PATRUNI, et al., 2016).

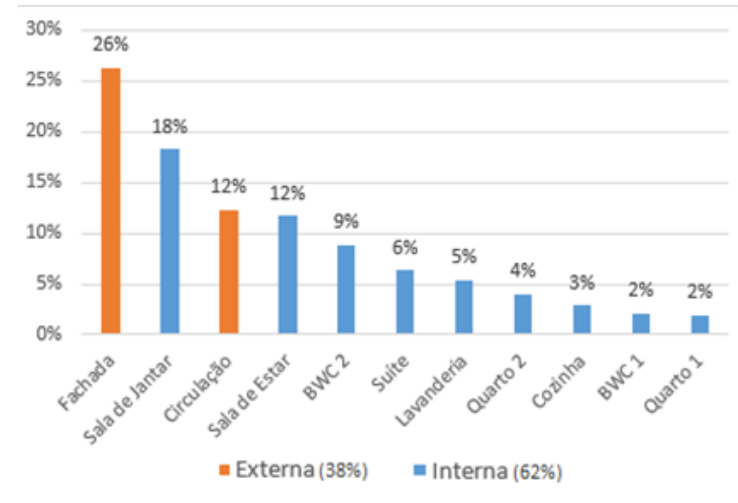

Figura 5: Frequência por região e por ambiente.

\subsection{Classificação quanto à origem.}

Com objetivo de investigar a natureza das manifestações patológicas, as anomalias foram classificadas quanto a sua origem seguindo a metodologia do IBAPE, apresentado na Figura 6.

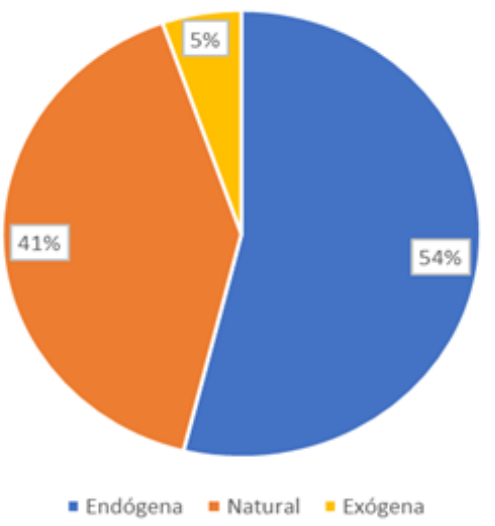

Figura 6: Classificação quanto à origem.

Observa-se que a maior parte das manifestações patológicas são de origem endógena (54\%) e natural (41\%). Neste estudo, as anomalias endógenas são em sua maior parte provenientes de falhas executivas e de planejamento. Além da possível ausência da armadura de reforço, já citada anteriormente, outro fator responsável por grande parte das anomalias encontradas, é a ausência de juntas de dilatação térmica, como pode-se visualizar na Figura 7.

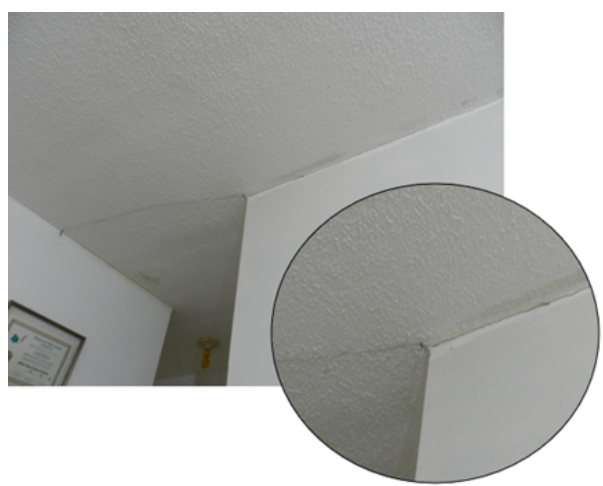

Figura 7: Fendas por variação térmica. 
A NBR 16055 (2012), atualmente em revisão, exige apenas a junta de dilatação a cada 25 metros da estrutura em planta, ou em casos de variações bruscas de geometria ou esforços verticais. Mehta e Monteiro (1994), citam que as tensões térmicas em estruturas de concreto decorrentes da variação de temperatura ocorrem devido as restrições externas e/ou internas às deformações do concreto, advindas da ligação das paredes com as demais estruturas, das ligações do concreto com a armadura e da coesão interna do próprio concreto.

Em alguns casos de manifestação de bolores, Figura 9, identificou-se que a causa era de origem natural. Como citado no Capítulo 2, o bolor é consequência do desenvolvimento de microorganismos. Muito comum em fachadas, estes microorganismos se desenvolvem a partir de chuvas típicas intensas sobre a parede exposta a uma temperatura constante e sem a ação do vento (SATO, 1997).

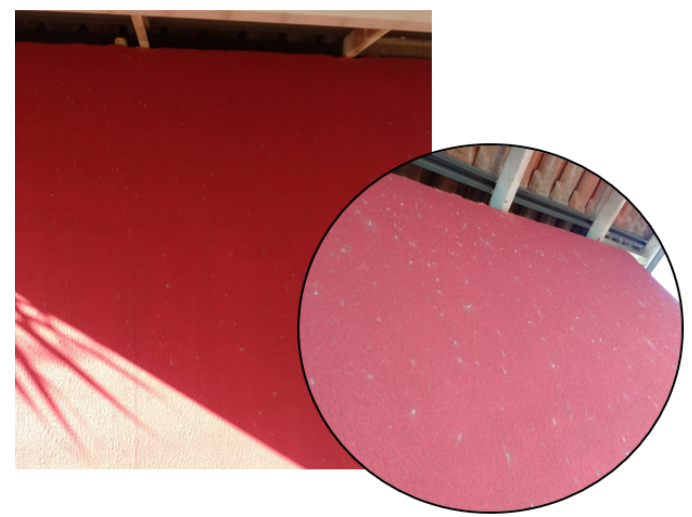

Figura 9: Bolor em fachada.

Já as patologias exógenas (5\%) correspondem às anomalias ocasionadas pelos próprios usuários, decorrentes do mau uso, como telhas quebradas que ocasionam infiltrações, furos inadequados nas paredes e principalmente a incorreta amarração de elementos construtivos em casos de ampliação. Neste estudo, as ampliações foram resultantes da opção de aquisição do imóvel sem a varanda, possibilitando aos moradores a construção de uma área aos fundos do lote sem a necessidade de seguir o padrão condominial.

A NBR 16055 (2012), estabelece que para prevenir o aparecimento de fissuras em paredes de concreto, deve-se analisar a necessidade de colocação de juntas verticais. A norma regulamenta que, tais juntas sejam definidas através de ensaios específicos e que na ausência dos mesmos deve-se adotar um espaçamento máximo de 8 metros entre juntas para paredes internas e 6 metros para paredes externas.

Entretanto, no caso de ampliações, por tratar-se de uma execução em um período diferente da obra inicial e também pela utilização de alvenaria convencional, há a necessidade de realizar uma amarração entre os elementos construtivos, evitando as fendas mostradas na Figura 10. Este tipo de amarração se assemelha, por exemplo, à ligação de paredes e pilares, onde se indica o uso de telas metálicas eletrossoldadas de arame galvanizado, empregadas para prevenir fissuras de interface entre alvenaria e pilar, devendo-se respeitar para isso, limites de flechas máximas do elemento de suporte (MEDEIROS e FRANCO, 1999).

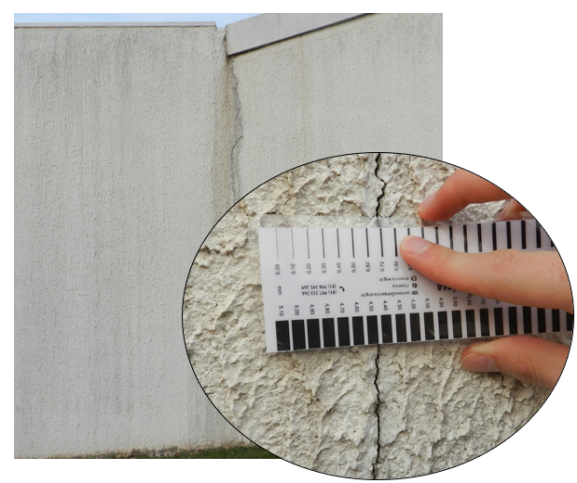

Figura 10: Fendas por falta de amarração. 
Observa-se que, não foram encontradas patologias de origem funcional, ou seja, decorrente do término da vida útil dos elementos.

\subsection{Classificação quanto ao grau de risco.}

Seguindo os parâmetros definidos pelo IBAPE na Norma de Inspeção Predial, as falhas foram classificadas de acordo com o risco oferecido aos usuários, ao meio ambiente e ao patrimônio pessoal, cujos percentuais estão mostrados na Figura 11.

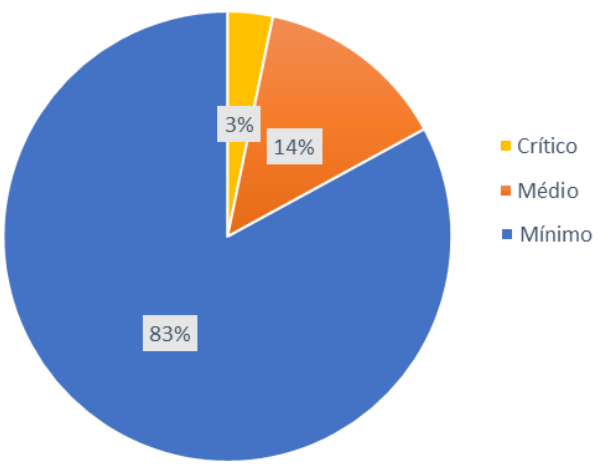

Figura 11: Classificação quanto ao grau de risco.

Constatou-se que $83 \%$ das manifestações patológicas apresentam grau mínimo, causando prejuízos à estética, como fissuras com espessuras mínimas e bolores no início de sua manifestação. As anomalias de criticidade média (14\%) correspondem às falhas onde o risco está na perda parcial de desempenho e funcionalidade com potencial para tornar-se uma patologia crítica como, fissuras com espessura próxima à 0,5 milímetros, trincas e bolores intermediários. Já as patologias críticas representam $3 \%$ das doenças.

Conforme já citado anteriormente, $70 \%$ das anomalias encontradas correspondem às fissuras. Entretanto, as fissuras equivalem a apenas $17 \%$ das manifestações patológicas que apresentam risco crítico, como se pode observar na Figura 12, que demonstra um comparativo relacionando a porcentagem que cada patologia representa entre as falhas encontradas e entre as falhas críticas.

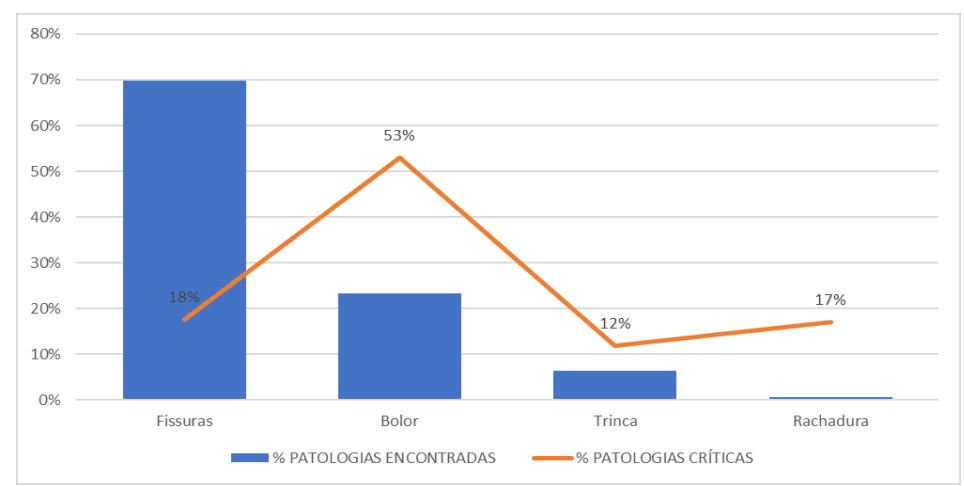

Figura 12: Patologias encontradas x Patologias críticas.

Observa-se que o bolor é a segunda patologia mais frequente e representa $53 \%$ das anomalias classificadas como críticas. Como já constatado anteriormente, a manifestação do bolor está diretamente ligada à presença de umidade, $\mathrm{o}$ que reitera a importância da impermeabilização durante a execução da obra, tendo em vista que sua ausência, ou sua utilização inadequada, compromete a durabilidade da edificação, podendo gerar problemas financeiros e danos à saúde dos usuários (BATISTA, et al., 2017).

As paredes do banheiro da suíte das casas são externas, porém a insolação é reduzida devido à cobertura da garagem. Outro fator importante que deve ser observado pelos usuários é abrir a janela do banheiro para garantir a ventilação natural no ambiente evitando o surgimento dos fungos, como o mostrado na Figura 13. 


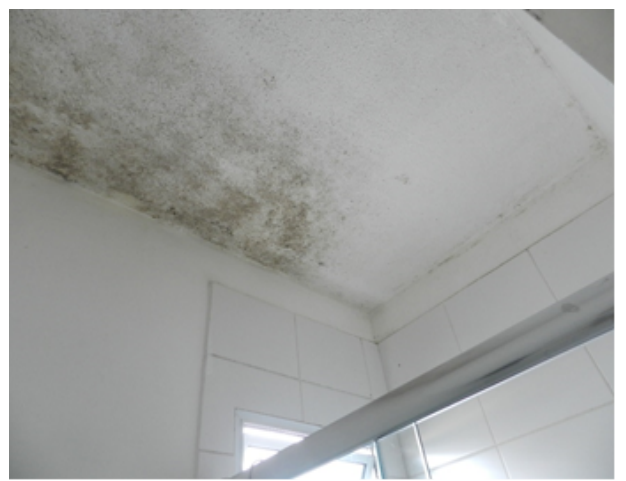

Figura 13: Manifestação de bolor no banheiro.

A fachada, área externa da suíte, é outro ambiente que possui um grau elevado de manifestações patológicas naturais, provenientes da ação das intempéries. Observa-se que em grande parte das amostras há presença de manchas esverdeadas iniciando na parte inferior da parede, o que pode ser visualizado na Figura 14. Além da umidade proveniente da chuva e do ar, provavelmente a umidade pode ser causada por capilaridade proveniente dos vazios do solo, ou devido a falta ou a má aplicação de impermeabilização do piso.

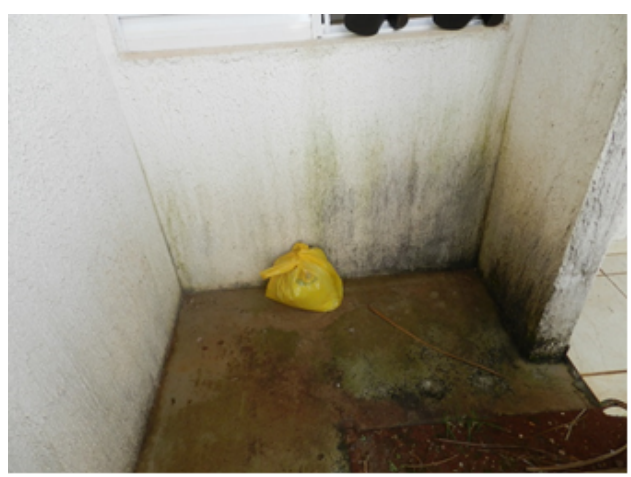

Figura 14: Manifestação de bolor na fachada.

\subsection{Método para recuperação de bolores}

A umidade nos materiais construtivos origina e abre caminhos para outros tipos de patologias na edificação. É preciso prevenir e aplicar ações corretivas evitando assim desconforto para as pessoas que convivem ou transitam no local (PAZ, et al., 2016). Caso não seja possível prevenir, e a patologia ocorra, a limpeza da superfície é necessária, com emprego de soluções fungicidas podendo até ocorrer a troca de materiais, que estavam contaminados por outros que resistam a ação de crescimento do bolor (SOUZA e SILVA, 2008).

Atualmente há no mercado diversos produtos fungicidas utilizados para combate aos microrganismos. Entretanto, podem-se utilizar soluções caseiras como alvejante com cloro e água (proporção de $30 \%$ cloro). A aplicação do produto se dá com escovas de cerdas duras e após a aplicação, a superfície deve ser lavada com água, até retirar todo o produto, e o aplicador deve usar equipamentos de proteção como luvas, óculos e máscara (SOUZA e SILVA, 2008).

No caso da persistência da manifestação dos microrganismos, recomenda-se a instalação de desumidificadores mecânicos e em casos extremos a completa substituição dos materiais das áreas contaminadas. Durante o processo de reconstrução é importante que sejam empregados materiais hidrofóbicos garantindo a estanqueidade da vedação final e, se possível, a realização de pintura antimofo (GUERRA, 2018).

\section{CONSIDERAÇÕES FINAIS}

Considerando o exposto, identificaram-se as manifestações patológicas do condomínio residencial localizado na cidade de Cascavel-PR, que foi executado no ano de 2009 em paredes de concreto moldadas in loco. Trata-se de um método construtivo, consideravelmente recente no país, regulamentado pela NBR 16055, publicada apenas em 2012. Foram feitas vistorias em 55 das 202 casas de modelo C, das quais 54 delas apresentaram algum tipo de problema, dentre eles foram levantados os mais frequentes: fissuras, trincas, rachaduras e bolores. 
Com base na coleta de dados, constatou-se que as fissuras foram as patologias mais encontradas, correspondendo a $70 \%$ do total, seguida pelos bolores (23\%), trincas $(6 \%)$ e por fim as rachaduras $(1 \%)$. A partir das referências bibliográficas, classificaram-se as anomalias em sua maioria de origem endógena (54\%), proveniente da falta de planejamento e da má execução, e natural (41\%) que podem ser decorrentes, principalmente das variações térmicas do concreto.

De acordo com o grau de risco, $83 \%$ das falhas são de criticidade mínima, causando pequenos prejuízos à estética e $14 \%$ de criticidade média. Dentre as anomalias identificadas como críticas (3\%) destacaram-se os bolores por corresponderem a mais da metade destas unidades (53\%). A incidência do bolor reflete na importância da impermeabilização durante a etapa de execução, principalmente em áreas molhadas, garantindo a estanqueidade dos materiais, visto que a presença destes microrganismos prejudica a vida útil das estruturas e principalmente a saúde dos moradores.

Os métodos indicados para reparo dos bolores podem variar desde a limpeza com soluções fungicida até a completa substituição dos materiais contaminados, podendo gerar despesas consideravelmente elevadas aos usuários. Reitera-se a importância dos engenheiros e arquitetos a não subestimar as ações das intempéries nos estudos preliminares da etapa de projeto, para garantir a ventilação e insolação ideal aos ambientes, assim como a aplicação de métodos preventivos.

\section{REFERÊNCIAS}

ASSOCIAÇÃO BRASILEIRA DE CIMENTO PORTLAD. Paredes de concreto - Coletânea de ativos. Jaguaré, (SP); $2007 / 2008$.

ASSOCIAÇÃO BRASILEIRA DE NORMAS TÉCNICAS, NBR 16055: Parede de concreto moldada no local para a construção de edificações - Requisitos e procedimentos. Rio de Janeiro, 2012.

BAKENS, W. Building pathology in a new context. In: Minutes of the First International Symposium on Building Patology, 2015, Porto. Porto: Faculty of Engineering University of Porto, 2015.

BAUER, E.; SANTOS, M. J.; PEREIRA, C. Metodologia de catalogação de fissuras em fachadas de edificações. In: Anais do Congresso Brasileiro de Patologia das Construções, 2018, Campo Grande. Porto Alegre: Associação Brasileira de Patologia das Construções (ALCONPAT BR), 2018.

BATISTA, P.; LOPES, P; SOUZA, R.; MONTEIRO, E. Manifestações patológicas causadas pela umidade devido à falha ou ausência de impermeabilização: estudo de caso. In: Anais da Conferência Nacional de Patologia e Recuperação de Estruturas, 2017, Recife. Recife: Escola Politécnica da Universidade de Pernambuco (POLI/UPE), 2017.

CAMADURO JR, I. W.; ZATT, P. J. R. Um estudo sobre fissuras em concreto armado. In: Encontro Tecnológico da Engenharia Civil e Arquitetura de Maringá, 2000, Maringá. Maringá: Universidade Estadual de Maringá (UEM), 2000 .

CAPORRINO, C. F. Patologia das anomalias em alvenarias e revestimentos argamassados. Téchne. São Paulo, 15 mai. 2016; Ed 110.

FRANCA, A.; MARCONDES, C. G.; ROCHA, F.; MEDEIROS, M.; HELENE, P. Patologia das construções: uma especialidade na engenharia civil. Disponível em:

<https://www.phd.eng.br/wp-content/uploads/2011/07/Artigo-Techne-174-set-2011-Prof.pdf> Acesso em: 20 mar. 2019.

GONÇALVES, E. A. B. Estudo de patologias e suas causas nas estruturas de concreto armado de obras de edificações. Disponível em: < http://monografias.poli.ufrj.br/monografias/monopoli10014879.pdf $>$ Acesso em: 17 mar. 2019.

INSTITUTO BRASILEIRO DE AVALIAÇÕES E PERÍCIAS. Norma de Inspeção Predial. São Paulo, 2012. 
MACEDO, J. V. S.; ROMEIRO, M. L. A.; DELMIRO, T. D.; MONTEIRO, E. C. B.; CARDOSO, A. S. Manifestações patológicas e falhas construtivas em paredes de concreto. In: $6^{\mathbf{a}}$ Conferência Sobre Patologia e Reabilitação de Edifícios, 2018, Rio de Janeiro. Rio de Janeiro: Universidade Federal do Rio de Janeiro (UFRJ), 2018.

MAIDEL, B.; ALMEIRA, F.; LIDANI, J.; FLACH, S. R. Patologias das edificações. Disponível em: $<$ https://speranzaengenharia.ning.com/page/patologias-das-edificacoes> Acesso em: 21 mar. 2019.

MEDEIROS, J. S.; FRANCO, L. S. Prevenção de trincas em alvenarias através do emprego de telas soldadas como armadura e ancoragem. Disponível em: < http://www.pcc.usp.br/files/text/publications/TT 00022.pdf> Acesso em: 03 set. 2019.

OLIVEIRA, D. F. Levantamento de causas de patologias na construção civil. Disponível em: $<$ http://monografias.poli.ufrj.br/monografias/monopoli10007893.pdf> Acesso em: 21 mar. 2019.

PATRUNI, Z.; VICENZI, F.; SCHACKOW, A.; GOMES, I. R.; EFFTING, C. Variação da Temperatura em Amostras de Concreto devido à Hidratação do Cimento. In: Anais do $26^{\circ}$ Seminário de Iniciação Científica da Universidade do Estado de Santa Catarina, 2016, Florianópolis. Florianópolis: Universidade do Estado de Santa Catarina (UDESC), 2016.

PIANCASTELLI, É. M. Patologia e Terapia das Estruturas: Reforço com Concreto. Universidade Federal de Minas Gerais. 31 p. Notas de Aula. 2005.

PINA, G. L. Patologia nas habitações populares. Rio de Janeiro, 2013. Disponível em:

$<$ http://monografias.poli.ufrj.br/monografias/monopoli10006577.pdf $>$ Acesso em 15 mar. 2019.

SAMPAIO, G. G. S.; COUTINHO, G. C.; NOGUEIRA, M. S.; MANIER, R. J. Patologia em paredes de concreto. Disponível em:

$<$ http://revista.universo.edu.br/index.php? journal=2TRABALHOSACADEMICOSAOGONCALO2\&page=article\&op $=$ viewFile\&path $\% 5 \mathrm{~B} \% 5 \mathrm{D}=3735 \&$ path $\% 5 \mathrm{~B} \% 5 \mathrm{D}=2416>$ Acesso em: 08 mar. 2019.

SATO, Neide Matiko Nakata; JOHN, Vanderley Moacyr; UEMOTO, Kai Loh. Umidade e crescimento de microrganismos em fachadas. In: Anais do III Seminário Internacional de Durabilidade de Materiais, Componentes e Estruturas, 1995, São Paulo. São Paulo, EPUSP, 1997, p.63-8.

SILVA, V. G.; SILVA, M. G. Análise do ciclo de vida aplicada ao setor da construção civil: revisão da abordagem e estado atual. In: Anais do VIII Encontro Nacional de Tecnologia do Ambiente Construído, 2000, Salvador. Salvador: Associação Nacional de Tecnologia do Ambiente Construído (ANTAC), 2000. V.1.

SOUZA, M. F.; SILVA, A. P. Patologias ocasionadas pela umidade nas edificações. Disponível em: $<$ http://especializacaocivil.demc.ufmg.br/trabalhos/pg1/Patologias $\% 20$ Ocasionadas $\% 20$ Pela $\% 20$ Umidade $\% 20$ Nas.pdf $>$ Acesso em: 18 mar. 2019.

SOUZA, V. C. M.; RIPPER, T. Patologia, Recuperação e Reforço de Estruturas de Concreto. São Paulo: Pini, 1998.

TACCO, R. M. C. A.; SILVA, A. P. Manifestações patológicas causadas por obras novas em edificações vizinhas. Disponível em:

$<$ http://www.bibliotecadigital.ufmg.br/dspace/bitstream/handle/1843/BUBD-AQ4EHV/monografia_regina_tacco.pdf?se quence $=1>$ Acesso em: 16 mar. 2019.

VITÓRIO, A. Fundamentos da patologia das estruturas nas perícias de engenharia. Disponível em:

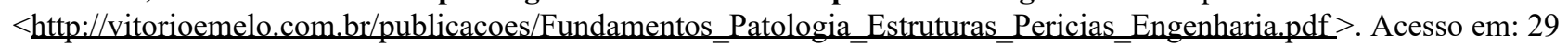
mar. 2019.

VERÇOZA, E. J. Patologia das Edificações. Porto Alegre, Editora Sagra, 1991.172p. 